\title{
UNA PERSPECTIVA JURÍDICA SOBRE LA DONACIÓN DEL REINO DE MURCIA A JAIME II DE ARAGÓN
}

\author{
Agustín BERMÚDEZ AZNAR
}

\section{EL ESTADO DE LA CUESTIÓN}

El tema de la conquista y anexión del reino de Murcia a la corona de Aragón ha sido objeto de una continuada atención historiográfica. El propio relato de los más destacados acontecimientos se encuentra ya en la mera narración cronística del suceso ${ }^{1}$, pero es que, además, disponemos de la documentación de la época en actualizada edición ${ }^{2}$ y de numerosos estudios que, incluso en nuestros días, siguen ofreciendo nuevas perspectivas y enfoques ${ }^{3}$.

1 Entre dichas crónicas destacan por su minuciosidad las aragonesas; especialmente la de $R$. MUNTANER (ed. de F. Soldevila en Les grandes croniques, Barcelona, 1971, cap. CLXXXVIII, pp. 834 y ss.) y la de J. ZURITA, Anales de la corona de Aragón (ed. de A. Canellas López, Zaragoza, 1969, lib. $V$, cap. XXI, pp. 501 y ss.).

2 Resultan fundamentales: la Colección de documentos para la historia del reino de Murcia. Documentos del siglo XIII, ed. de J. Torres Fontes, Murcia, 1969; El reino de Murcia bajo Aragón (12961305). Corpus documental, ed. de J.M. del Estal, vol. $1 / 1$, Alicante, 1985, y vol. I/2, Alicante, 1990. (En adelante esta colección será citada: J.M. del Estal, $1 / 1$ o l/2).

En un contexto más amplio siguen aportando documentos de interés los clásicos estudios de $M$. GAIBROIS DE BALLESTEROS, Historia del reinado de Sancho IV de Castilla, Madrid 1922-1929, y A. BENAVIDES, Memorias del reinado de Don Fernando $N$ de Castilla, Madrid 1860. En un segundo plano se encuentran algunos documentos de interés en A. GIMÉNEZ SOLER, Don Juan Manuel, Zaragoza, 1932.

3 Entre ellos cabe mencionar: J. M. DEL ESTAL, Conquista y anexión de las tierras de Alicante, Elche, Orihuela y Guardamar al reino de Valencia por Jaime l/ de Aragón (1296-1308), Alicante, 1982; M.T. FERRER Y MALLOL, "Notes sobre la conquesta de Murcia per Jaume II (1296-1304)", en el Homenatge a la memòria del Prof. Emilio Sáez. Aplec d'estudis dels seus deixebles i col-laboradors. 
Pero, frente a todo ello, la valoración jurídica de la anexión no ha merecido tanto interés bibliográfico. Y ello no cabe justificarlo por la menor entidad del tema; por el contrario, puede afirmarse que, en buena medida, el proceso de incorporación aragonesa gira en torno al eje articulador que jurídicamente supone una donación, esto es, un acuerdo de voluntades tendente a producir la traslación de un dominio. Desde este supuesto se comprende que Jaime II no dejase de esgrimir en ningún momento la donación como el instrumento jurídico legitimador de su presencia en las tierras del levante castellano.

En la documentación de la época ha quedado clara constancia de la importancia que se le asignó por todos a la donación. Así, al pedir D. Jaime a $D^{a}$ Yolanda Manuel y a su marido el infante $\mathrm{D}$. Alfonso de Portugal que reconociesen su soberanía en relación con los señoríos murcianos que poseían, les argumenta que lo hace porque le es «feita donaçión purament entre vivos del reino de Murçia, con su carta, por la qual cosa el dito regno perteneçe a Nos, e Nos somos venidos agora en el dito Regno por omperar e reçebir aquél así como a cosa nuestra» ${ }^{4}$. Igualmente, en 1296, el arraez de Crevillente Mahomat Abenhudell justifica su sumisión «cercioratus plenarie de donatione et concesione facta vobis ilustrissimo domino Jacobo... irrevocabiliter inter vivos de toto Regno Murcie... per illustrissimum dominum Alfonso... per hostensionem instrumenti publici de donatione et concesione ${ }^{5}$. De forma similar, los vecinos de Orihuela rinden pleito-homenaje a Jaime II «per rao de la donatio al dito senyor Rey en Jacme feta purament et entre vius per lo molt alt senyor Namfos, per la graçia de Deu, rey de Castella... segons que es contengut en la carta publica de la dita donatio, bollada amb bolla de plomb» ${ }^{6}$.

Pero, no cabe duda que una donación como la del reino de Murcia constituyó un acto jurídico complejo, en el que cada uno de sus principales elementos componentes: donante, objeto donado y donatario aglutinaron en torno suyo abundantes y no fácilmente resolubles problemas.

\section{EL DONANTE: D. ALFONSO DE LA CERDA}

\section{Legitimidad de su titularidad}

La primera problemática a tratar debe referirse a la persona del donante: D. Alfonso de la Cerda, hijo del infante D. Fernando de Castilla. Y la crucial cuestión que a él

Barcelona, 1989, pp. 27-44; A. MASIÁ DE ROS, Relación castellano-aragonesa desde Jaime ll a Pedro el Ceremonioso, Barcelona, 1994; E. GUINOT, Els limits del Regne, Valencia, 1995, especialmente el cap. 7, pp. 103-115.

4 1296-abril-28. Huerta de Almoradí. Carta de Don Jaime II al infante D. Alfonso de Portugal. (En J.M. DEL ESTAL, I/1, doc. 8 y $1 / 2$, doc. 12).

5 1296-mayo-17. Huerta de Murcia. Acta de sumisión del arraez de Crevillente Mahomat Abenhudell a Jaime II reconociéndole como soberano del reino de Murcia. (En J.M. DEL ESTAL, 1/1, doc. 66).

6 1296-mayo-11. Orihuela. Pleito-homenaje de la villa de Orihuela a Jaime II de Aragón. (En J.M. DEL ESTAL, I/1, doc.18). 
afecta respecto a la donación es la legitimidad de su título de propiedad o señorío sobre el reino de Murcia. Se trata obviamente de un problema complejo y difícil, pues está conectado y es consecuencia de la conflictividad sucesoria desencadenada tras la muerte del príncipe heredero D. Fernando?.

A este respecto, y enfocando el tema tan sólo en la vertiente que es objeto de nuestro interés y no en la globalidad del debate, cabe puntualizar que, como tópicamente se viene repitiendo, según el Derecho tradicional castellano la muerte en 1275 del heredero al trono de Castilla, sin haber accedido a la titularidad real, no transmitía derechos al trono a sus sucesores; por eso, el texto legal castellano posiblemente vigente en ese momento, el Espéculo, no contemplaba, al abordar el supuesto, la posible existencia de un derecho de representación por parte de los sucesores del difunto ${ }^{8}$. Sin embargo, el gran texto legal alfonsino, las Partidas, sí recoge este principio de representación especificando que "si el hijo mayor muriese antes que heredase, si hubiera hijo o hija de su mujer legítima, que aquel o aquella lo hubiese (el reino) y no otro»'; lo que ocurre es que resulta dudoso y problemático aceptar la vigencia en dicha fecha de este último texto ${ }^{10}$. En cualquier caso es lo cierto que, no sin dilación y vacilaciones, Alfonso $X$ hará jurar como heredero a su segundo hijo, el infante $D$. Sancho, siguiendo, en definitiva, la normativa tradicional castellana y dándose, en teoría, por acabado el tema. De esta forma terminaban las aspiraciones a ocupar el trono castellano por parte de D. Alfonso, el hijo mayor del infante fallecido; por lo menos aquí terminarían sus derechos al mismo por el mecanismo de la sucesión forzosa.

Pero posteriores acontecimientos políticos volverían a reabrir el tema sucesorio desde un planteamiento jurídico distinto: Se trata de la rebelión del legítimo heredero, el infante $D$. Sancho, contra su padre, el rey Alfonso $X$, acontecimiento igualmente complejo y oscuro. El hecho es que esta situación repercutió en el tema sucesorio ya que si bien la sucesión del infante tenía carácter forzoso no lo es menos que cabía su exclusión en caso de mediar justa y grave causa. Y la concurrencia de estas circunstancias fue lo que llevó al rey Alfonso $X$ a desheredar solemnemente a su hijo el 8 de octubre de $1282^{11}$. Tan grave medida fue ratificada en el testamento del monarca de 8

7 E. BENITO RUANO, «El problema sucesorio de Castilla a la muerte de D.Fernando de la Cerda», en VII Centenario del Infante Don Fernando de la Cerda. Jornadas de Estudio. Ciudad Real, 1976, pp. 217-225.

8 Así, en Il.16.1 el texto legal se limita a declarar tan sólo que «el fijo mayor del rey deue heredar el señorío de su padre». (Seguimos la edición de G. Martínez Díez, Ávila, 1985).

9 II.15.2.

10 Parece inoperante respecto al tema aquí tratado entrar en el complejo y debatido problema del inicio de la vigencia legal de las Partidas. Véase como opinión recogida en una actualizada obra de conjunto: Salvador DE MOXÓ, “La época de Alfonso X», en Historia de España dirigida por J.M. Jover Zamora. Tomo XIII, vol.: «La expansión peninsular y mediterránea. La corona de Castilla». Madrid, 1990; especialmente el cap. VII: «La sucesión de Castilla», pp. 200 y 204.En el mismo sentido: M. GONZÁLEZ JIMÉNEZ, Alfonso X (1252-1284). Palencia, 1993, p. 129.

11 Un amplio comentario y glosa del documento se encontrará en A. BALLESTEROS BERETTA, Alfonso $X$ el Sabio, Barcelona, 1963, p. 992.

La legalidad de la medida a tenor del Espéculo II.6.2 era inequívoca: «e deven ser deseredados 
de noviembre de 1283, alegando el intento del infante de despojar a su propio padre de sus reinos y señoríos. Y por si se abrigaba alguna duda al respecto, el rey ratifica su decisión en su codicilo de 1284 ya que por medio del mismo era también dado desheredar ${ }^{12}$.

Pues bien, en consonancia con cuanto antecede, y desde un plano teórico-jurídico, la vía de acceso al trono de Castilla, que se le había cerrado a D. Alfonso de la Cerda por el mecanismo de la sucesión forzosa, se le abría ahora de nuevo; esta posibilidad se basaba en su nombramiento como heredero testamentario por parte de su abuelo, el rey Alfonso $X$, una vez desheredado Don Sancho.

No obstante todo ello, y como es bien sabido, D. Sancho, públicamente maldecido y desheredado por su padre, accede de facto al trono de Castilla, y como tal es jurado y reconocido por todos.

\section{El uso, reconocimiento y capacidad real del donante}

La ocupación del trono de Castilla por Sancho IV no impidió que terminasen las reivindicaciones del primogénito del fallecido infante $\mathrm{D}$. Fernando. Muy por el contrario, D. Alfonso de la Cerda mantuvo en todo momento sus legítimas aspiraciones al trono de Castilla amparándose en la voluntad testamentaria de su abuelo Alfonso $X$. En consecuencia, utilizó la correspondiente y tradicional titulación real, incluso llegando como tal a suscribir tratados de paz y alianza ${ }^{13}$. Ese tratamiento le es reconocido además por algún soberano extranjero ${ }^{14}$, pero, sobre todo, por Jaime II, quien suele dirigirse a él como «llustrem Dominum Alfonsum, Regem Castelle» o como «muy noble y muy honrrado Don Alfonso, por la gracia de Dios, Rey de Castilla...» ${ }^{15}$; en contrapartida y coherentemente, Jaime II calificará a Fernando IV como "Don Ferrando qu' es diu Rey de Castiella» o «Ferdinandus qui se dicit Regem Castelle, natus quodam dopni Sancii de Castella» ${ }^{16}$.

Es más, en dos ocasiones Don Alfonso será formalmente proclamado rey de Castilla.

de todo cuanto que ovieren por siempre, e áyalo el rey para darlo o para fazer dello lo que quisiere». También Partidas VI.7.4 permitía de forma genérica que el padre desheredase al hijo que "le buscase tan mal porque el padre oviese a perder gran partida de lo suyo e menoscabar".

12 Los comentarios y referencias de A. Ballesteros a estos testamentos pueden verse en su obra Alfonso $X$ el Sabio, ob. cit., pp. 1000 y 1050 respectivamente.

Partidas VI.12.2 también permitía desheredar en codicilo.

13 1301-septiembre-10. Zaragoza. Tratado de paz entre Don Alfonso de la Cerda y el rey de Granada Muahmmad II. (En J.M. DEL ESTAL, 1/2, doc. 202).

14 1300-marzo-28. Carta del sultán de Egipto a Don Alfonso, rey de Castilla. (J.M. DEL ESTAL, I/2, doc.112).

15 Son múltiples los ejemplos documentales aducibles a este respecto. Sin ánimo de exhaustividad, véanse algunos de ellos en J.M. DEL ESTAL, I/1, doc. 80; y I/2, docs. 5, 44, 45, 90, 91, 98, 99 y 228.

16 Entre los ejemplos documentales citables véanse en J.M. DEL ESTAL, $1 / 1$, doc. 68 ; y $1 / 2$ docs. 168, 169, 193 y 204. También se encuentra alguna similar referencia en A. JIMÉNEZ SOLER, Don Juan Manuel, ob. cit., doc. LXXXII. 
Una en Jaca, en 1288, y otra en Sahagún, en 1296; en ambas se realizó una ceremonia formal de aclamación por parte de un grupo de nobles castellanos leales a su causa $^{17}$. Obvia y consecuentemente con todo ello D. Alfonso no llegó en ningún momento a renunciar formalmente a su dignidad real y a sus derechos al trono castellano; precisamente por eso una de las cláusulas de los acuerdos arbitrales de Torrellas de 1304 estableció "que el dicho Don Alonso dexe la voz de Rey de Castilla y de León, como se llama Rey, et las armas derechas et sello de Rey"18.

Así pues, Don Alfonso siempre se creyó legítimo rey y consiguientemente legítimo detentador del señorío sobre las tierras de la corona de Castilla. $Y$ dentro del conjunto de prerrogativas reales a él inherentes, $D$. Alfonso de la Cerda, en cuanto pretendido rey castellano, tenía la tradicional facultad de hacer donaciones; tal disponía la legislación ${ }^{19}$ y tal era, y había sido, la práctica en la vida política castellana. Por ello nada de extraño puede encontrarse en el hecho de que $D$. Alfonso, en uso de sus legítimas prerrogativas reales, done uno de los territorios de su señorío, el reino de Murcia, al Rey de Aragón, su pariente y, sobre todo, su continuo valedor.

\section{LA DONACIÓN DEL REINO DE MURCIA}

\section{Licitud de la donación de un reino}

El objeto de la generosa donación por parte de D. Alfonso era nada menos que de todo un reino, el reino de Murcia. Pero la magnitud de la donación es tal que cabe preguntarse sobre la licitud de donar uno de los componentes territoriales de la corona de Castilla, con la violación que ello podía suponer del principio de la indivisibilidad del patrimonio territorial de la corona que se heredaba.

En el orden de los principios, el propio Alfonso X se había mostrado contrario a cualquier práctica que pudiera comportar una desmembración del patrimonio territorial de la corona. Ya en 1255, con motivo del juramento de su hija $D^{\text {a }}$ Berenguela como presunta heredera de la corona castellana, el monarca hace especial hincapié en este extremo ${ }^{20}$. Posteriormente, en su magna obra legal, las Partidas, se establece que el rey y todos los del reino deben «guardar que el señorío sea todavía uno, e non consientan en ninguna manera que se enajene nin se departa» ${ }^{21}$.

17 J.M. DEL ESTAL, Conquista y anexión del reino de Murcia, ob. cit., pp. 160 y 166. Para una más amplia contextualización histórica de la crisis civil castellana véase. C. GONZÁLEZ MíNGUEZ: Fernando IV (1295-1312). Palencia, 1995, pp. 13-146.

18 En A. BENAVIDES, Memorias del reinado de D. Fernando IV, ob. cit., vol. II, doc. 280; J.M. DEL ESTAL, I/1, doc. 214.

19 Partidas, II.1.8, II.5.15 y V.4.9 contemplan la posibilidad de generosas donaciones reales, aunque sin llegar nunca a preveer la amplitud de la que nos ocupa.

20 W. PISKORSKI, Las Cortes de Castilla. Ed. facs. Barcelona, 1977. Ap. I, pp. 196-197.

21 II.15.5. Este argumento se vuelve a reiterar en II.15.2 al tratar de «como el fijo mayor ha adelantamiento e mayoría sobre los otros hermanos». 
Sin embargo, en los planteamientos teóricos de la política castellana sorprende constatar como se cuenta habitualmente con los reinos para resolver los más variados problemas políticos. Así, siguiendo con el ejemplo suministrado por el propio Alfonso $\mathrm{X}$, el monarca castellano, para condescender a las presiones de Felipe III de Francia en favor de los infantes de la Cerda, decide separar a Jaén y concederlo como reino vasallo a Don Alfonso ${ }^{22}$; la tajante oposición del heredero, el infante D. Sancho, hace fracasar el plan. Mas tarde, en 1283, al desheredar en Sevilla a D. Sancho e instituir como heredero a D. Alfonso de la Cerda, el viejo monarca castellano dona los reinos de Sevilla-Badajoz a su hermano, el infante $D$. Juan, y el reino de Murcia a su otro hermano el infante D. Jaime ${ }^{23}$; es cierto que ambos territorios tenían la condición de reinos vasallos de Castilla, pero no lo es menos que se trata de un débil vínculo, tendente a superar formalmente la posible objeción que pudiera hacerse de ir contra el mencionado principio de indivisibilidad del territorio de la corona castellana.

Con estos próximos antecedentes nada de extraño hay en que, pocos años después, se vuelva a utilizar el fraccionamiento territorial de la corona castellana como instrumento negociador para conseguir componendas políticas que ayuden a resolver problemas coyunturales. Así, el 21 de enero de 1296 tiene lugar en la localidad de Ariza un peculiar reparto teórico de la corona castellana entre Don Alfonso de la Cerda y su tío, el infante D. Juan; por él se adjudican al infante $D$. Juan los reinos de León, Galicia y Sevilla, y a D. Alfonso los de Castilla, Toledo Córdoba, Murcia y Jaén ${ }^{24}$; de la trascendencia práctica de este reparto puede juzgarse a tenor de la proclamación real de D. Juan en León y de D. Alfonso en Sahagún, ceremonias ambas celebradas ese mismo año de 1296. Posteriormente, el 26 de junio de 1303, cuando ya decae claramente la estrella política del pretendiente rey $\mathrm{D}$. Alfonso, en una reunión también habida en Ariza entre Jaime II, el infante D. Enrique, D. Diego López de Haro, su hijo y D. Juan Manuel para intentar una vez más buscar una solución negociada al conflicto castellano, se adopta entre otros acuerdos el de conseguir de D. Fernando IV de Castilla la concesión para D. Alfonso de la Cerda del reino de Jaén y algunas otras villas ${ }^{25}$.

Aunque es evidente que todos estos proyectos y propuestas en ningún momento llegaron a materializarse, es lo cierto también que son denotadoras de la viabilidad con la que teóricamente se planteaba la posibilidad de donar un reino.

22 Los detalles sobre la entrevista de Bayona de 1280 pueden encontrarse en A. BALLESTEROS BERETTA, Alfonso $X$ el Sabio, ob. cit., p. 928.

23 A. BALLESTEROS BERETTA, Alfonso $X$ el Sabio, ob. cit., pp. 1053-1054. Véase la interpretación que del alcance de estas donaciones hace M. GONZÁLEZ JIMÉNEZ, Alfonso X, ob. cit., pp. 152 y 153.

24 J.M. DEL ESTAL, Conquista y anexión, ob. cit., p. 165.

25 1303-junio-20. Ariza. Alianza realizada entre D. Enrique, D. Diego López de Haro, D. Juan Manuel y D. Jaime II, el infante D. Alfonso y el infante D. Fernando. (En A. BENAVIDES, Memorias de Fernando IV de Castilla, ob. cit., vol. II, doc. 234. Véase también el vol. I, pp. 15 y 29). 


\section{Formalización de la donación}

En dos ocasiones tiene formalmente lugar la donación del reino de Murcia por parte del pretendiente y titulado rey de Castilla D. Alfonso de la Cerda.

La primera se hace a favor de $D$. Alfonso de Aragón en documento expedido en Calatayud el 26 de junio de 1289.

Este documento comienza con la titulación real del donante, a la que sigue la motivación de la liberalidad que la provoca (ayuda especial prestada para ganar sus reinos empleando sus vasallos y tesoros), la calificación del acto jurídico (donación) y su duración («por agora e pora todos los tiempos»).

En cuanto al objeto donado, tras denominarlo globalizadamente (el reino de Murcia y su señorío) pasa a detallarlo a partir de tres niveles: físico, personal y material; respecto al primero incluye los mares, ríos, aguas, montes, llanos, ciudades (especifica las de Murcia y Cartagena), villas, lugares, castillos y fortalezas; respecto al componente personal alude expresamente a los hombres, caballeros, infanzones, dueñas, ciudadanos, clérigos y habitantes cristianos, judíos y moros; en relación al elemento material se conceden las rentas, pechos, pedidos y derechos debidos por razón del señorío.

Los derechos incluidos en la donación son también objeto de minuciosa relación. Ante todo el donante declara hacer al donatario rey y señor del objeto donado, es decir del ámbito físico (reino, ciudades, villas y lugares), del poblacional (los habitantes, ciudadanos, caballeros y otros hombres) y del elemento material (rentas y derechos que a los reyes de Castilla tradicionalmente le correspondieron). Al propio tiempo se reconoce en el donatario su capacidad plena para dar, vender y cambiar lo que estime oportuno, sin que por lo tanto el donante se haga reserva alguna en ninguna proporción, renunciando expresamente a cualquier derecho o señorío que le pudiera corresponder. En consecuencia, el donante pone al donatario en señorío y derecho del bien donado, y manda a todos los ricos hombres, caballeros, dueñas, infanzones, clérigos, ciudadanos y hombres del reino de Murcia que lo tengan desde ese momento por su rey y señor, absolviéndoles, para facilitar ese reconocimiento, de toda fe, homenaje y naturaleza que le hubieran prestado o le fueran debidos.

Entre las cláusulas complementarias contenidas en el documento figuran las promisorias de no retener el donante nada del reino, y de que cuanto de alguna manera le pueda venir o percibir será desde ahora en voz del nuevo rey. También figuran las cláusulas de no retrocesión e irrevocabilidad de la donación, y una serie de cláusulas asegurativas: de reconocimiento y homenaje, de observancia de lo estipulado (ratificado con juramento sobre la cruz) y de formalidad escrita, mediante la expedición de carta sellada.

Con la obligada datación, relación de testigos, etc., termina este importante documento ${ }^{26}$.

26 En J.M. DEL ESTAL, $1 / 1$, doc. 1. 
Respecto a la segunda donación, la efectuada a Jaime II en Ariza el 21 de enero de 1296, debió tener un contenido similar a la anterior y pudo ser efectiva y nuevamente formalizada en documento, ya que tanto D. Alfonso de la Cerda ${ }^{27}$, como D. Jaime $\|^{28}$ aludirán a dicho instrumento jurídico.

Conviene tener en cuenta que con la mera expedición del documento de donación tan sólo se cumplía por parte del donante una de las formalidades del acto jurídico (tal vez la más importante), pero restaban, sin embargo, otras que, con carácter complementario, contribuían también a su perfeccionamiento. Las que se encuentran en la donación del reino de Murcia fueron: la notificación de la donación a terceros interesados, el mandato de su cumplimiento, y el público reconocimiento de la misma.

El testimonio más elocuente de la notificación de la donación a posibles terceros implicados, unida a la orden de su cumplimiento, es una carta de Don Alfonso dirigida al concejo de Orihuela el 3 de febrero de 1296; en ella le comunica la donación que ha realizado, ordena obediencia al nuevo titular, el rey de Aragón, y les absuelve expresamente de la fe, jura, homenaje, fidelidad y naturaleza que a él le fuera debida como rey de Castilla ${ }^{29}$.

El reconocimiento ostensible y público de la donación por parte de $\mathrm{D}$. Alfonso de la Cerda consistió en la supresión de su titularidad real sobre Murcia en cuantos documentos expide desde ese momento, manteniendo obviamente los restantes títulos reales en el inicio de todas sus cartas.

\section{EL DONATARIO: DON JAIME II DE ARAGÓN}

En principio, hay que presumir en el donatario la concurrencia de los elementales requisitos legales que le capacitaban para recibir la donación. Tan sólo podrían plantearse dudas referidas a su condición de no natural, requisito éste nada superfluo en un caso en que el bien donado era un reino. A este respecto cabe considerar que tal exigencia no debia tener un carácter taxativo, pues en otras parcelas del Derecho público castellano su operatividad era escasa; tal es el caso frecuentísimo de los matrimonios reales e incluso también el de los derechos sucesorios. A este último respecto debe recordarse que entre las previsiones sucesorias del propio Alfonso X figuraba la de llamar a la sucesión de la corona de Castilla, si ello fuera preciso, al propio rey de Francia, Felipe III ${ }^{30}$.

27 "Como Nos ayamos dado el Regno de Murcia... por nuestras cartas seelladas con nuestra bulla de plomo colgada». (En J.M. DEL ESTAL, I/1, doc. 3).

28 1296-abril-28. Huerta de Almoradí. Carta de Jaime Il al infante portugués Don Alfonso: «A Nos feita donaçión purament entre vivos del Regno de Murçia con su carta». (En J.M. DEL ESTAL, 1/1, doc.8).

29 Véase la nota 27.

30 En A. BALLESTEROS BERETTA, Alfonso $X$ el Sabio, ob. cit., p. 1007. 


\section{La aceptación de la donación}

Si bien no tenemos constancia de una declaración expresa de Jaime II respecto a su aceptación de la donación, la misma puede inferirse desde el primer momento de incidentales referencias documentales. Por ejemplo, la contenida en una carta de 28 de abril de 1296 en la que el monarca aragonés declara a $D^{a}$ Yolanda de Portugal que por la donación que se le ha realizado «el dito regno perteneçe a Nos... e Nos somos venidos agora en el dito Regno por reçebir aquél así como a cosa nuestra»; o también en la alusión contenida en la carta de Jaime II dirigida al conde de Ampurias donde expresamente alude al «regnum nostrum Murcie» 31.

Pero son más bien ciertas actuaciones del mencionado rey las que inequívocamente permiten inferir su actitud. La primera es la incorporación que hace del título de rey de Murcia en todos los documentos emanados de su Cancillería; su ubicación la hará tras el de Valencia, siguiéndole después el de conde de Barcelona ${ }^{32}$. La segunda es la notificación que personalmente hace a cuantos puedan estar implicados en el tema de la concesión y su nueva condición de rey de Murcia; a tales efectos es de mencionar la carta dirigida a su consejero Bernat de Sarriá el 17 de febrero de 1296, notificándole la terminación de las negociaciones y mandándole se disponga a ocupar por la fuerza las plazas y lugares del reino de $\mathrm{Murcia}^{33}$; en el mismo sentido se expresa al infante D. Alfonso de Portugal al pedirle su reconocimiento como rey y señor del reino de Murcia por cuantos castillos y lugares allí tenía ${ }^{34}$.

\section{Ocupación y reconocimiento}

La ocupación de la donación efectuada era en el terreno práctico el gran problema a resolver ya que, como es obvio, se dona un reino perteneciente a la corona de Castilla, a la que habitantes, ciudades, villas, lugares, castillos, fortalezas y señoríos enclavados en el reino murciano reconocen como legítima entidad soberana.

En este sentido, la actitud táctica de D. Jaime fue clara. Comenzó anteponiendo el despliegue de un contingente militar para asediar y ocupar, si fuera necesario, cada localidad o enclave militar que se le opusiera; al propio tiempo, se sirvió de un amplio conjunto de medidas pacíficas, que desde las más duras amenazas podían llegar a

31 «Por la qual cosa (donación) el dito Regno perteneçe a Nos, e Nos somos venidos agora en el dito Regno por omperar e reçebir aquél, así como a cosa nuestra". (En J.M. DEL ESTAL, I/1, doc. 8, y $\mathrm{I} / 2$, doc. 193 respectivamente).

32 Así, pues, la titulación real pasa de la tradicional: «Don Jaime, por la gracia de Dios, Rey de Aragón, de Mallorcas, et de Valencia, et conde de Barcelona» (documento de 1296-abril-29, en J.M. DEL ESTAL, I/1, doc. 9) a la de «En Jacme, por la gracia de Deu, Rey d'Aragó, de Mallorques, de Valentia, de Murçia et Comte de Barcelona» (documento de 1296-mayo-11, en J.M. DEL. ESTAL, I/1, doc. 18).

33 J.M. DEL ESTAL, $1 / 1$, doc. 5.

34 «Porque vos requerimos e vos amonestamos que vos nos ayades e nos obedescades por aquello que tenedes en el Regno de Murçia, como a señor e rey del Regno de Murçia». (En J.M. DEL ESTAL, $1 / 1$, doc. 8). 
las más generosas promesas; de esta forma se trató de evitar el efectivo uso de las armas y la consecución del tan deseado reconocimiento ${ }^{35}$.

Respecto a la actuación militar sólo hubo algún combate aislado (por ejemplo el mantenido ante el castillo de Alicante) bastando, en general, el asedio formal como medio intimidatorio. Respecto a las medidas pacíficas, Jaime II dio muestras de su acrisolada habilidad diplomática y negociadora; en esta táctica los instrumentos más utilizados fueron la expedición de salvoconductos que facilitaran mantener entrevistas negociadoras ${ }^{36}$, el establecimiento de treguas que permitieran a las poblaciones asediadas recapacitar sobre su decisión ${ }^{37}, y$, cuando no hubo más remedio, el uso de conminaciones y amenazas, sobre todo de expropiación de heredamientos ${ }^{38}$.

Fruto de la eficacia de todas estas medidas fue que el monarca aragonés consiguiera poco a poco tomar posesión del reino donado y obtener el reconocimiento de su soberanía y señorío por parte de las autoridades militares, núcleos poblacionales y señoríos asentados en el reino de Murcia.

En cuanto a los primeros, el reconocimiento de los responsables de las instalaciones militares resultaba fundamental. Pero no todos los alcaides de castillos y fortalezas reaccionaron del mismo modo; los hubo que, como el alcaide de Alicante Nicolás Pérez, se opuso hasta el final y murió en la refriega; otros, sin embargo, tras una más o menos corta resistencia terminaron doblegándose y reconociendo la soberanía aragonesa. En consonancia con dichas actitudes el tratamiento que les dispensó Jaime II fue muy variado; en los casos de mayor colaboración y rápido reconocimiento se les recompensó, cuando menos, con la confirmación en el oficio (circunstancia ésta que debió ser uno de los señuelos de la negociación) ${ }^{39}$; en otros casos la pérdida del cargo e, incluso, la sanción fueron inevitables ${ }^{40}$.

35 El detalle de la progresiva ocupación de cada plaza y las medidas adoptadas al efecto pueden seguirse con detalle en J.M. DEL ESTAL, Conquista y anexión, ob. cit., pp. 183-268.

36 Pueden servir como ejemplo los salvoconductos otorgados en mayo de 1296 al alcaide de Alhama, de Monteagudo y de Chocos. (En J.M. DEL ESTAL, 1/1, docs. 59, 70 y 84 respectivamente).

37 Así, entre otras, las dadas a Cartagena en 22 de mayo de 1296, (en J.M. DEL ESTAL, I/1, doc. 87). Pero posiblemente las más reiteradas y complejas fueron las concedidas a Don Juan Manuel por su señorío de Elche en 17 de mayo de 1296, 27 de julio de 1296 y, sobre todo, de 9 de mayo de 1303. (En J.M. DEL ESTAL 1/1, docs. 57, 124 y 195 respectivamente).Véase también R. CHAVÁS, "Treguas de Don Jaime Il de Aragón con el noble Don Juan Manuel, hijo del infante Don Manuel", en Boletín de la Real Academia de la Historia, 28 (1896), pp. 433-440.

38 Resulta paradigmático a estos efectos la carta de Jaime II a Lorca el 17 de diciembre de 1300. (En J.M. DEL ESTAL, I/2, doc. 129).

39 Tal fue el caso, entre otros, de Miguel García, alcaide de Abanilla (J.M. DEL ESTAL, Conquista y anexión, ob. cit., p. 215), Pedro Roys de San Cebrián, alcaide del castillo de Orihuela (ibídem, p. 221), Juan Fernández de Gomariz, alcaide del castillo de Monteagudo (ibídem, p. 240), Pedro Zapata, alcaide del castillo de Mula (ibídem, p. 252) y Romeu de Merimond, alcaide del castillo de Cartagena (ibídem, p. 254).

40 Así actuó Jaime Il contra el alcaide castellano de Callosa, Fernando Pérez de Gurmesal, a quien no sólo destituye sino que también sanciona con la confiscación de sus bienes. Otro tanto le ocurrió al alcaide del Castillo de Cartagena, Sancho Díaz de Bustamante. (En J.M. DEL ESTAL, Conquista y anexión, ob. cit., pp. 214 y 257). 
En relación a los núcleos poblacionales, el reconocimiento se produce tras la consiguiente negociación y promesas del nuevo monarca de respetar las personas de los pobladores, sus privilegios y propiedades. Tal ocurre con algunos ejemplos documentados que disponemos de Orihuela, Murcia y Elche; en todos ellos, un grupo de procuradores o miembros del concejo, dotados de los consiguientes poderes al efecto acudian ante el monarca o su representante para prestarle el obligado homenaje y reconocimiento. En Orihuela, en concreto, el acto se realiza por el concejo reunido en la Iglesia de San Salvador, haciéndole a Jaime II homenaje «de boca y de manos» como a su rey y señor natural ${ }^{41}$. También de Lorca conocemos los nombres de sus representantes que llevaron a cabo el "sacramentum fidelitatis et homagium ore et manibus Bernardo de Serriano, nomine Domini Regis, et recognoverunt dictum dominum regem pro rege et domino regni Murcie» ${ }^{42}$.

Por último, como ejemplo elocuente del reconocimiento por parte de un lugar de señorío, disponemos del acta por la que Mahomat Abenhudell, ra'is de Crevillente, «recognoscens in verum et naturalem dominum meum vos predictum dominum regem Jacobum ${ }^{43}$.

\section{Los actos de disposición del donatario}

A partir del reconocimiento de Jaime II como nuevo señor, éste, en uso de la soberanía que detenta sobre el territorio, realiza toda una serie de actos de disposición de índole muy diversa.

En primer lugar se encuentran toda una serie de concesiones privilegiadas a colectividades urbanas y confesionales. Respecto a las primeras fueron muy numerosos los privilegios de todo tipo concedidos a ciudades y villas que, tras la oportuna negociación terminan reconociéndole como rey; la recompensa real consistió las más de las veces en la confirmación de sus propiedades, los indultos por encausaciones civiles o criminales, libertad de tránsito por los reinos, etc. ${ }^{44}$. Otro tanto ocurre con las comunidades confesionales. A las comunidades de mudéjares se les suelen dar seguridades personales y patrimoniales para evitar que huyan y se despueblen los lugares donde habitan ${ }^{45}$; además de ello se les reconocen sus propios tribunales para el cono-

41 1296-mayo-11. Orihuela. Reconocimiento de Jaime II como rey de Murcia por el concejo de Orihuela. (En J.M. DEL ESTAL, 1/1, doc. 18).

42 1300-diciembre-19. Lorca. Relación de caballeros lorquinos que prestaron homenaje a Jaime II. (En J.M. DEL ESTAL, I/2, doc. 132).

43 1296-mayo-17. Ante el castillo de Monteagudo. Acta se sumisión de Mahomat Abenhudell, arraez y señor de Crevillente, reconociendo a Jaime II como soberano del Reino de Murcia y su señor natural. (En J.M. DEL ESTAL, I/1, doc. 66).

44 Un buen ejemplo de este tipo de medidas nos lo suministran las efectuadas por Jaime II para Orihuela el 11 de mayo de 1296 y que se recogen en J.M. DEL ESTAL, I/1, docs. 16-34.

45 Véanse a este respecto las garantías generales reflejadas en una carta real de Jaime II a todos los mudéjares del reino de Murcia el 20 de mayo de 1296. (En J.M. DEL ESTAL, 1/1, doc.79).

Las hay también referidas específicamente a los sarracenos de Alguazas, Cartagena, Petrel y Elche. (En J.M. DEL ESTAL, 1/1, docs. 75, 97, 59 y 189 respectivamente). 
cimiento de sus causas ${ }^{46}$, la celebración de mercado semanal ${ }^{47}$, exenciones de servicios personales ${ }^{48}$, exenciones impositivas ${ }^{49}$, etc. Menos abundantes fueron, pero tampoco faltaron, las disposiciones referidas a judíos: extensión a los mismos de los privilegios concedidos a los vecinos de la localidad ${ }^{50}$, exención del «ius hospiti» ${ }^{51}$, libertad de tránsito ${ }^{52}$, etc.

Dentro de las concesiones privilegiadas menudearon las de carácter estrictamente personal. En algunos casos se trata de licencias militares ${ }^{53}$, en otras son salvoconductos, como el concedido al Adelantado del Reino de Murcia, D. Juan Sánchez de Ayala para abandonar con su familia y enseres el reino de Murcia en un plazo de tiempo determinado ${ }^{54}$; no faltan tampoco perdones e indultos a inculpados ${ }^{55}$. Pero en la mayoría de las ocasiones estos privilegios contienen recompensas a los leales colaboradores a la causa aragonesa; estas recompensas fueron, sobre todo, inmuebles que habían sido confiscados a sus anteriores propietarios por traición o por no haber reconocido a tiempo la soberanía del nuevo monarca ${ }^{56}$; en menor proporción también se efec-

46 A efectos judiciales y procesales son importantes dos disposiciones de Jaime II. En una, de 23 de mayo de 1296, nombra al ra'is de Crevillente como juez ordinario de todos los sarracenos moradores de Crevillente, Alicante, Orihuela, Guardamar y Beniopa, (en J.M. DEL ESTAL, I/2, doc. 51). La otra se refiere específicamente a la aljama sarracena de Alicante para que sus causas sean sustanciadas según la çunna, (en J.M. DEL ESTAL, Alicante, de villa a ciudad 1252-1490, Alicante, 1990, doc. 45).

47 El 19 de febrero de 1298 Jaime II concede a los sarracenos de Guardamar la celebración de un mercado semanal. (En J.M. DEL ESTAL, 1/1, doc. 161).

48 Una exención de la prestación de servicio militar a los mudéjares de la Arrixaca y huerta de Murcia es la concedida por Jaime II el 25 de abril de 1303. (En J.M. DEL ESTAL, 1/1, doc. 193).

49 En 1303 Jaime II eximirá de cabezaje y alfarda a los mudéjares de la Arrixaca y huerta de Murcia y también a los de Elche. A estos últimos les eximirá además de la tarchana. (En J.M. DEL ESTAL, $\mathbf{I} 1$, doc. 188,190 y 191 respectivamente).

50 Tal hace Jaime II respecto a los judíos de Alicante el 9 de febrero de 1298. (En J.M. DEL ESTAL, I/1, doc. 160).

51 Esta exención referida a la aljama de judíos de Murcia respecto a los miembros de la familia real es ratificada por Jaime II el 3 de junio de 1296. (En J.M. DEL ESTAL, I/1, doc. 98).

52 Un ejemplo contundente de esta libertad de desplazamiento lo muestra el privilegio de guiatge y salvoconducto dado por Jaime II para los judíos de Cartagena el 3 de junio de 1296. (En J.M. DEL ESTAL, $1 / 1$, doc. 97).

53 Se trata de licencias para permitir el regreso a casa de hombres de armas ya en grupos ya aisladąmente. (Véanse, por ejemplo, las concedidas por Jaime ll los días 14,15 y 17 de mayo de 1296, recogidas en la obra de J.M. DEL ESTAL, I/2, docs. 34,36 y 38; también en $1 / 1$, doc. 53).

54 En J.M. DEL ESTAL, l/2, doc. 37.

55 Así los concedidos el 16 de mayo de 1296 a dos vecinos de Alicante, Julián y Pedro Martínez de Alcañiz. (En J.M. DEL ESTAL, l/1, docs. 54 y 55).

56 La documentación recoge variados ejemplos de estas concesiones inmobiliarias efectuadas por Jaime II a sus leales colaboradores. Véanse en J.M. DEL ESTAL, I/1, docs. 11, 93 111, 112, 113, $123,131,133,135$, y en $1 / 2$, docs. $27,29,30,31,35,101,102,256,257,258,259,261,262$ y 271. 
tuaron concesiones de rentas ${ }^{57}$ e incluso de oficios ${ }^{58}$. Los destinatarios de todas estas medidas casi siempre eran cristianos, y cuando aparecen destinatarios mudéjares suelen ser de alto nivel social, como el arraez de la Arrixaca de Murcia $^{59}$ o la esposa del ra'is de Crevillente ${ }^{60}$.

Otra prototípica manifestación de la soberanía del nuevo titular fue el ejercicio de una ordinaria actividad legislativa. En este sentido, la emanada de Jaime II tuvo en principio la pretensión de infundir confianza a la población y facilitar al máximo su aceptación de la soberanía aragonesa; para lograrlo se mantuvieron incólumes los fueros, privilegios, exenciones y costumbres locales, muchos de ellos conseguidos y disfrutados ya desde época de Alfonso X. Esta medida debió aplicarse de forma radical tan sólo en un primer momento, y se intentaría con ella no sólo facilitar el suave tránsito a la nueva soberanía sino también ganar tiempo mientras que se elaboraba un marco legal más amplio, al parecer inspirado en la legislación vigente en el reino de Valencia. El caso de Murcia es a tales efectos paradigmático: la ciudad, tras reconocer a Jaime II, recibe una primera confirmación de su tradicional Derecho, para señalársele como supletorio el Fuero de Valencia en tanto que se realizaba para ella una específica recopilación; ésta fue efectivamente sancionada por el monarca el 25 de octubre de 1297, y aunque no se conoce el texto completo de la misma su entronque con la legislación valenciana es incuestionable ${ }^{61}$.

En cuanto al aparato institucional de gobierno y administración, el original castellano es sustituido por el aragonés. A nivel territorial tal ocurre con el Adelantamiento del Reino de Murcia, que es transmutado ahora por una Procuración General del Reino de Murcia ${ }^{62}$. Otro tanto cabría decir respecto al oficio de Bayle General del Reino de

57 Suelen ser, en su mayoría, rentas anuales renovables a beneplácito real; excepcionalmente las hay vitalicias, y en un caso se concede una renta diaria de carácter vitalicio. (En J.M. DEL ESTAL, $\mathrm{l} / 1$, docs. $134,135,136,138,139,140,145$, y I/2, docs. 67 y 68 ).

58 1296-agosto-4. Jaime Il otorga a Juan de Marsella el oficio de corredor en Orihuela; tiene carácter vitalicio y de recompensa a los servicios prestados. (En J.M. DEL ESTAL, I/2, doc. 65).

59 La concesión que le hace Jaime II en 1296 de un horno, casa urbanas y seis fanegas de tierra de cultivo puede verse en J.M. DEL. ESTAL, $1 / 1$, doc. 92.

60 Jaime II le confirma el heredamiento que le había legado en Murcia su padre, el rey moro Aliafar. (En J.M. DEL ESTAL, 172, doc. 52).

61 En este sentido resultan muy elocuentes tres misivas de Jaime II. La primera de 3 de julio de 1296 está dirigida al justicia de Murcia, mandándole servirse de los fueros otorgados a la ciudad por Alfonso $X$ y sus sucesores en tanto se lleva a cabo una "compilatio Fori Murcie»; en caso de no encontrarse solución legal en los mencionados textos se recurriría a los Furs de Valencia. La segunda carta, de la misma fecha que la anterior, está dirigida a los juristas Martín de Dios y Juan Meeyani, encomendándoles la realización de una compilación del Fuero de Murcia. La tercera, de 25 de octubre de 1297, es una provisión real dirigida a sus súbditos del reino de Murcia notificándoles haber sancionado el Forum Murcie. (En J.M. DEL ESTAL, l/1, docs. 113,114 y 148 respectivamente). Véase también sobre toda esta temática: J.M. DEL ESTAL, “El Fuero y las Constitutiones Regni Murcje de Jaime II de Aragón (1296-1301)", en Anales de la Universidad de Alicante. Historia Medieval, 8 (1990-91), pp. 19-56.

62 El tránsito institucional se produce pronto. El 23 de mayo de 1296 Jaime II nombra a su hermanastro Jaime Pérez como Procurador General del Reino de Murcia, (en J.M. DEL ESTAL, 1/1, doc. 
Murcia $^{63}$, institución prototípica de la corona aragonesa, y por lo tanto hasta ese momento desconocida en los organigramas castellano-murcianos. A nivel local los cambios son también notables; así, y por no citar sino algunas de las más conocidas instituciones locales, los alcaldes y alguaciles de los núcleos poblacionales castellanos son sustituidos por justicias, jurados, baile y almotacén de las localidades aragonesas $^{64}$. Es posible, por último, que el cambio afectara menos a las autoridades militares, entre las que destacarían los alcaides; todo parece indicar que éstos mantendrían un ámbito competencial similar basado en el común vínculo de derechos y obligaciones generados por las relaciones vasalláticas; buena prueba de ello lo constituye el hecho de que la mayoría de los alcaides que se someten sin ofrecer resistencia son confirmados en su cargo por el nuevo monarca aragonés ${ }^{65}$.

En suma, la donación del reino de Murcia constituyó el pretexto e instrumento jurídico que, revalidado por la efectiva ocupación militar y reconocimiento formal, contribuyó a operar el tránsito de la soberanía castellana a la soberanía aragonesa. Un tránsito evidentemente coyuntural que la sentencia de Torrellas-Elche se encargaría de precisar en lo territorial y consolidar en lo temporal.

91). A partir de él se sucederán en el cargo D. Jaime de Xérica, Bernat de Sarriá, Bernat de Cruylles, Pedro de Monteagudo, etc.

63 Desde mayo de 1296 menudea la documentación sobre actuaciones de Bernat Colomet como Bayle General del Reino de Murcia; y desde 1301 ocurre otro tanto con su sucesor Ferrer Descortell. (J.M. DEL ESTAL, I/1, docs. 112, 129, 152, 171, y l/2, docs. 44, 45, 46, 47, 48 y 84).

64 Véase la carta privilegio de Jaime II a la villa de Alicante para que nombre justicia, jurados y almotacén en sustitución de los alcaldes y alguaciles, (en J.M. DEL ESTAL, 1/1, doc. 118). Sobre bayles locales la documentación también es abundante; respecto al de Alicante, por ejemplo, véanse las referencias de J.M. DEL ESTAL, Alicante de villa a ciudad, ob. cit., docs. 37, 39, 62, y 66.

65 Véase la nota 39. 